\title{
GENOMIC DEOXYRIBONUCLEIC ACID EXTRACTION FROM POST MORTEM FETAL
} TISSUE

\author{
S. Addison ${ }^{1}$, N.J. Sebire ${ }^{2}$, L. Judge-Kronis ${ }^{2}$, A.M. Taylor ${ }^{3}$, D. Abrams ${ }^{3}$, R. Scott ${ }^{4}$, N.J. Robertson ${ }^{5}$, D.

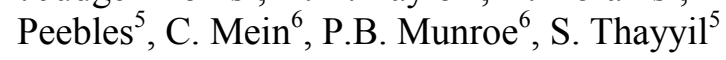 \\ ${ }^{1}$ Academic Neonatology, University College of London, ${ }^{2}$ Histopathology, Great Ormond Street Hospital for \\ Children NHS Trust, ${ }^{3}$ Cardiology, Institute of Child Health, ${ }^{4}$ Histopathology, University College London \\ Hospital NHS Foundation Trust, ${ }^{5}$ Academic Neonatology, UCL, ${ }^{6}$ Genome Centre and Clinical \\ Pharmacology, Queen Mary University of London, London, UK
}

A major challenge in post-mortem (PM) genetic testing in fetuses is the difficulty in obtaining high quality deoxyribonucleic acid (DNA) due to maceration. We examined the yield and quality of DNA from various PM fetal tissues.

Methods: Fresh tissue samples from the muscle, kidney, liver, heart and placenta from 14 consecutive fetuses were collected at the time of autopsy and stored at $-20{ }^{\circ} \mathrm{C}$. We extracted DNA using Promega Wizard Genomic DNA Purification Kit and assessed the DNA yield and quality using the Thermo Scientific Nanodrop and by agarose gel electrophoresis. Polymerase chain reaction (PCR) for genomic testing using 'in house' control primers was performed (Ethics approval: 10/H0713/26).

Results: The median (inter quartile range) gestation of the fetuses was $22(17,31)$ weeks and the PM interval was $5.5(3.7,7.7)$ days. Muscle, kidney and placenta gave the highest average yields for non-degraded genomic DNA. Liver DNA had lowest quality; this was due to tissue degradation

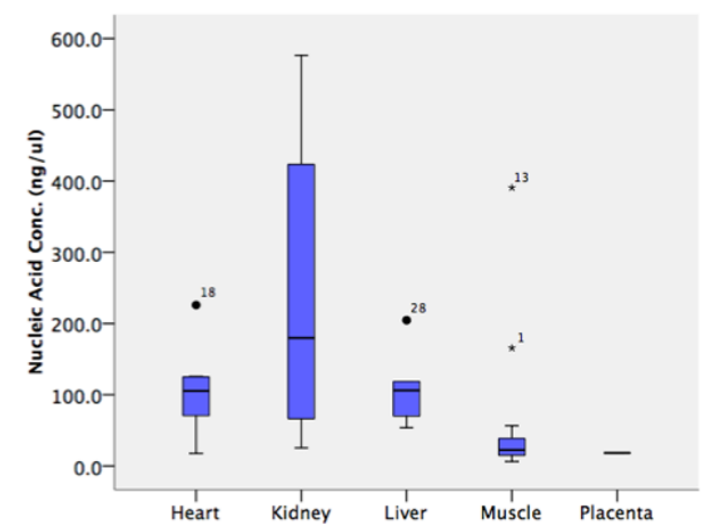

[DNA yield from various fetal tissues]

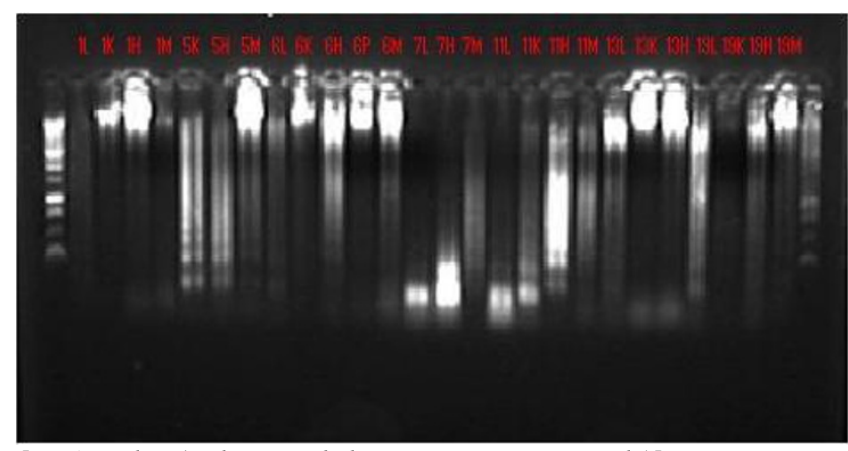

[DNA quality (L=liver, $K=$ kidney, $H=$ Heart, $M=$ muscle)]

. PM interval or gestational age did correlate with DNA yield or quality.

Conclusion: High quality genomic DNA can be extracted from fetal kidney, muscle and placenta at autopsy, despite advanced maceration. 